\title{
Oral premedication for paediatric ambulatory anaesthesia: a com- parison of midazolam and ketamine
}

To compare the clinical characteristics of two oral premedicants, midazolam and ketamine, 40 heallhy children, one to six years of age, who were scheduled for ambulatory dental surgery, were assigned to receive either oral midazolam $0.5 \mathrm{mg} \cdot \mathrm{kg}^{-1}$ or oral ketamine $5.0 \mathrm{mg} \cdot \mathrm{kg}^{-1}$ in a double-blind, randomized study. Sedation and anxiolysis scores before induction, cooperation at induction of anaesthesia and recovery times and complications were assessed. We found that both drugs effectively sedated the children within 20 min of administration. Although sedated, $10 \%$ of the children in the midazolam group and $20 \%$ of those in the ketamine group became tearful on separation from their parents and $20 \%$ of those in the midazolam group and $35 \%$ of those in the ketamine group became tearful when the facemask was applied. No important side effects were attributable to either premedication. The time until the children were fit for discharge from the hospital afier midazolam was approximately 20 min less than afier ketamine. In conclusion, midazolam and ketamine offer similar clinical characteristics when used as oral premedications for children undergoing ambulatory surgery, although the time to discharge from hospital may be more rapid afier midazolam than after ketamine.

\section{Key words}

ANAESTHESIA: paediatric, ambulatory;

PREMEDICATION: oral premedication, midazolam, ketamine;

SURGERY: dental.

From the Department of Anaesthesia, The Hospital for Sick Children and The Research Institute, The University of Toronto, 555 University Avenue, Toronto, Ontario, Canada M5G 1 X8

Address correspondence to: Dr. Jerrold Lerman, Department of Anaesthesia, The Hospital for Sick Children, Toronto, Ontario M5G 1 X1.

Accepted for publication 19th November, 1993.
Cette étude compare les caractéristiques cliniques de deux prémédications orales, le midazolam et la kétamine. Quarante enfants bien portants, âgés d'un à six ans, programmés pour une chirurgie ambulatoire dentaire, sont assigné au hasard et à double insu pour recevoir per os soit du midazolam 0,5 $\mathrm{mg} \cdot \mathrm{kg}^{-1}$, soit de la kétamine $5 \mathrm{mg} \cdot \mathrm{kg}^{-1}$. On enregistre les scores de sédation et d'anxiolyse avant linduction, l'attitude collaboratrice, la durée de la période de réveil et les complications. Nous avons trouvé que les deux produits produisent une sédation efficace dans les vingt minutes qui suivent leur administration. Bien que, sous sédation, $10 \%$ des enfants du groupe midazolam et $20 \%$ de ceux du groupe kétamine pleurent lors de la séparation parentale. Vingt pourcent des patients du groupe midazolam et $35 \%$ du groupe kétamine pleurent lorsque le masque est appliqué au visage. Aucune des prémédications ne provoque d'effets secondaires importants. Le moment du congé hospitalier est plus court d'environ 20 min après le midazolam. En conclusion, en tant que médications préopératoires, le midazolam et la kétamine présentent des caractéristiques identiques lorsquills sont utilisés en chirurgie pédiatrique ambulatoire mais le patient qui a reçu le midazolam reçoit son congé de l'hôpital plus rapidement que celui qui a reçu de la kétamine.

Numerous premedications have been advocated to facilitate the separation of children from their parents and to reduce the anxiety associated with the unfamiliar and intimidating environment of the operating theatre. The fact that no single premedication has achieved universal acceptance suggests that each has disadvantages.

The ideal premedication for ambulatory anaesthesia in children, one to six years of age, should possess the following attributes:

1 an acceptable, atraumatic route of administration

2 rapid and reliable onset

3 minimal side effects

4 rapid elimination

Recent reports have indicated that both oral midazolam $^{1-4}$ and oral ketamine ${ }^{5,6}$ fulfill many of these 
characteristics and both may be useful premedications for ambulatory paediatric anaesthesia. We therefore designed the following study to compare the advantages and disadvantages of midazolam and ketamine in the ambulatory setting.

\section{Methods}

After approval by the Human Subjects Review Committee, written informed consent was obtained from the parents of 40 children scheduled for dental surgery in our ambulatory unit. The inclusion criteria included:

1 age between one and six years

2 ASA physical status I or II without central nervous system disease

3 abstinence from sedative or hypnotic drugs within the month preceding surgery

4 absence of allergies to benzodiazepines and ketamine

5 ambulatory dental surgery scheduled for up to two hours in duration

Children were assigned by random selection using random number tables ${ }^{7}$ to one of two premedications in a volume of $0.1 \mathrm{ml} \cdot \mathrm{kg}^{-1}$ : midazolam $0.5 \mathrm{mg} \cdot \mathrm{kg}^{-1}(5$ $\mathrm{mg} \cdot \mathrm{kg}^{-1}$ parenteral formulation) or ketamine 5.0 $\mathrm{mg} \cdot \mathrm{kg}^{-1}\left(50 \mathrm{mg} \cdot \mathrm{kg}^{-1}\right.$ parenteral formulation). Both medications were diluted in $0.2 \mathrm{ml} \cdot \mathrm{kg}^{-1}$ of chocolatecherry syrup, mixed thoroughly and administered to the children by their parents.

The reactions of the children to the taste of the premedication were noted. If the premedication was not completely ingested or retained, that child was excluded from further analysis. The randomization code of the excluded child was then assigned to the next child enrolled in the study.

Demographic data including age, weight and the extent of sedation and anxiolysis before premedication were recorded. Sedation and anxiolysis were assessed at baseline (before premedication), at 5, 10,15 and 20 (separation of the child from his/her parents) min after administration of the premedication and at induction of anaesthesia (Table I). All measurements of separation and anxiolysis in this study were completed by the same investigator (PJA) to minimize interobserver variability. The observer was blinded to the premedication administered. Twenty minutes after administration of the premedication, each child was separated from his or her parents and taken directly to the operating room for induction of anaesthesia.

A final assessment of sedation and anxiolysis was made at the time of application of the face mask at induction of anaesthesia. Nitrous oxide (70\%) in oxygen was administered via the mask and breathing circuit. A cannula was then inserted into a peripheral vein and anaesthesia was induced with thiopentone $5 \mathrm{mg} \cdot \mathrm{kg}^{-1}$ and atropine
TABLE 1 Scoring of sedation and anxiolysis

\begin{tabular}{ll}
\hline Sedation & Anxiolysis \\
\hline 1 Alert/agitated & Combative \\
2 Awake & Tearful \\
3 Drowsy & Apprehensive \\
4 Asleep & Calm \\
\hline
\end{tabular}

$10-20 \mu \mathrm{g} \cdot \mathrm{kg}^{-1} \dot{\sim}$. Succinylcholine $1-2 \mathrm{mg} \cdot \mathrm{kg}^{-1}$ was then administered to facilitate nasotracheal intubation. Anaesthesia was maintained with halothane, at an inspired concentration titrated to stable vital signs, in $70 \%$ nitrous oxide and oxygen. The lungs were ventilated mechanically.

At the conclusion of surgery, all anaesthetic drugs were discontinued simultaneously. The trachea was extubated when the child had resumed spontaneous ventilation and the gag reflex had returned. Analgesia in the recovery room was administered if the child complained of pain at the site of surgery or was difficult to console. Acetaminophen was administered as the analgesic of choice unless the pain was severe enough to warrant parenteral morphine or oral codeine. Discharge from the same day unit required stable vital signs, that the child be awake and alert, and that he/she tolerated clear fluids.

The times from discontinuation of anaesthesia until extubation, spontaneous eye opening, oral fluid intake and discharge from the same day unit were recorded. Side effects and analgesic requirements were noted. The parents were asked to complete a questionnaire regarding their child's anaesthetic experience (see Appendix).

\section{Sample size estimation ${ }^{8}$}

To estimate an appropriate sample size for this study three assumptions were made: $\alpha_{2}=0.05, \beta=0.20$ and an effect size based on reported differences in the time to spontaneous eye opening after oral premedication with midazolam or ketamine. ${ }^{3,6} \mathrm{~A}$ minimum sample size of 17 children was determined. To allow for increased variability in the effect size, 20 children were included in each group. ${ }^{8}$

\section{Statistical analysis?}

Parametric data were reported as arithmetic means \pm standard deviation and analyzed using Student's unpaired $t$ test. For sedation measurements, the proportion of children who were drowsy at each measurement period was compared with the proportion at baseline using Chisquare analysis. For anxiolyis measurements, the proportion of children who were calm at each measurement period was compared with the proportion at baseline using Chi-square analysis. Nominal data (incidence of 
vomiting) were analyzed using Fisher's exact test. Statistical significance, $P<0.05$, was accepted.

\section{Results}

Seven of the 47 children who were initially recruited for the study refused to take their premedication. Forty children were divided equally between the two groups. The groups were matched with respect to age, weight, sex distribution and ASA physical status (Table II).

Four children $(20 \%)$ complained of the bitter taste of the midazolam preparation. None of the children in the ketamine group complained of the taste of the premedication. Surprisingly, one child from each group wanted more of the premedicant syrup.

The groups were similar with respect to the interval from administration of premedication until induction of anaesthesia, the duration of surgery and the time from discontinuation of anaesthesia until extubation, spontaneous eye opening and first oral intake (Table III).

Within $20 \mathrm{~min}$ of administration of the premedication, sedation in the two groups was similar: most children became drowsy (Figures 1 and 2$)(P<0.001)$. None of the children lost consciousness (indicated as "Asleep" in Figures 1 and 2) or required airway support.

With regard to anxiolysis in the midazolam group, the proportion of calm children at $15 \mathrm{~min}(P<0.001)$ and at the time of separation from their parents $(P<0.05)$ was greater than the proportion at baseline (Figure 3 ). The proportion of calm children at induction of anaesthesia was similar to that at baseline. The proportion of children who were tearful was similar at all times.

In contrast, in the ketamine group, only the proportion of calm children at $15 \mathrm{~min}$ was greater than at baseline $(P<0.01)$ (Figure 4). The proportions of calm children at separation and induction of anaesthesia were similar to that at baseline. The proportion of children who were tearful/combative at induction of anaesthesia was greater than at both $10(P<0.05)$ and $15(P$ $<0.01$ ) $\min$.

At the time of separation from their parents, $70 \%$ of the children in the midazolam group and $65 \%$ of those in the ketamine group were calm whilst $10 \%$ in the midazolam group and $20 \%$ in the ketamine group were tearful (Figures 3 and 4).

When the face mask was applied, $80 \%$ of the children in the midazolam group and $65 \%$ in the ketamine group remained calm or apprehensive. However, $20 \%$ in the midazolam group were tearful and $35 \%$ in the ketamine group were tearful or combative (Figures 3 and 4).

In the recovery room, the nurses administered analgesia to four children who had been premedicated with midazolam and to eight premedicated with ketamine. In the midazolam group, three received acetaminophen elixir
TABLE II Demographic data

\begin{tabular}{lll}
\hline & Midazolam & \multicolumn{1}{c}{ Ketamine } \\
\hline Age $(\mathrm{yr})^{*}$ & $3.5 \pm 1.1$ & $3.4 \pm 1.3$ \\
Weight $(\mathrm{kg})^{*}$ & $15.8 \pm 3.0$ & $14.9 \pm 1.3$ \\
Sex $(\mathrm{m} / \mathrm{f}) \dagger$ & $11 / 9$ & $11 / 9$ \\
ASA P/S $(\mathrm{I} / \mathrm{II}) \dagger$ & $18 / 2$ & $17 / 3$ \\
\hline
\end{tabular}

*Means $\pm \mathrm{SD}$.

$\nmid$ Numbers of patients.

TABLE III Study time intervals

\begin{tabular}{lcc}
\hline & Midazolam & Ketamine \\
\hline Premedication to induction & $21.8 \pm 7.0$ & $23.1 \pm 5.8$ \\
Induction to end of surgery & $67.9 \pm 21.2$ & $76.4 \pm 25.8$ \\
End of surgery to extubation & $6.4 \pm 2.8$ & $6.8 \pm 3.1$ \\
End of surgery to spontaneous & & \\
$\quad$ eye opening & $39.0 \pm 16.5$ & $32.0 \pm 16.5$ \\
End of surgery to oral intake & $57.0 \pm 12.3$ & $63.8 \pm 24.5$ \\
End of surgery to discharge home & $90.0 \pm 22.3$ & $110.7 \pm 28.1^{*}$ \\
\hline
\end{tabular}

All times (min) are means \pm SD.

$* P<0.05$ compared with midazolam.

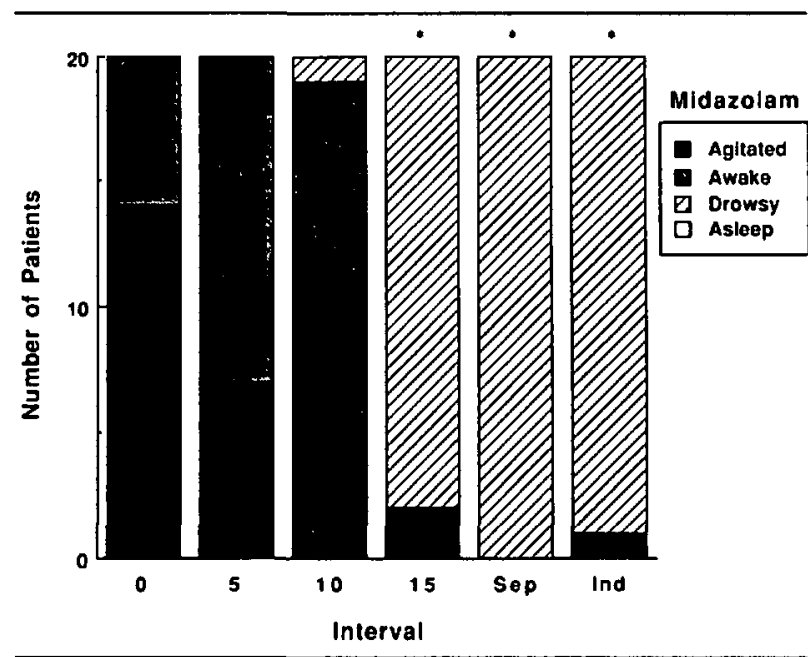

FIGURE 1 The frequency of sedation scores after oral midazolam premedication. Interval 0 corresponds to baseline measurements (before premedication), intervals 5,10 and 15 are the respective time intervals (min) after premedication. Sep is the time separation of the child from their parents and Ind is the time of mask application. - $P<0.001$ refers to the number of drowsy children at each time interval compared with the baseline frequency.

and one received intravenous morphine sulfate whilst in the ketamine group six received acetaminophen elixir and two received oral codeine phosphate. No patient received more than one dose of analgesic medication. 


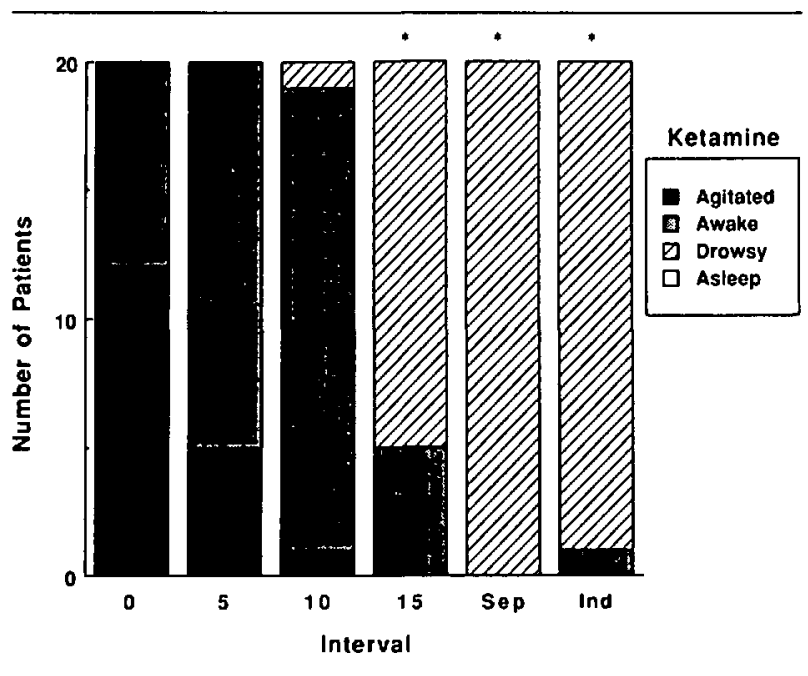

FIGURE 2 The frequency of sedation scores after oral ketamine premedication. ${ }^{*} P<0.001$ refers to the number of drowsy children at each time interval compared with the baseline frequency.

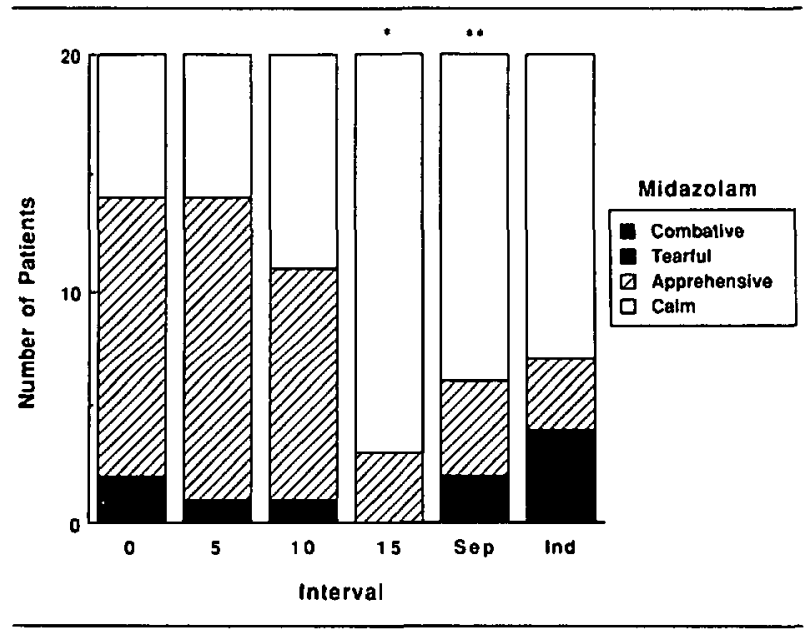

FIGURE 3 The frequency of anxiolysis scores after oral midazolam premedication. $* P<0.001$ and $* * P<0.05$ refers to the number of calm children compared with the baseline frequency.

Postoperative vomiting occurred in one patient in the midazolam group and in three patients in the ketamine group ( $P=\mathrm{NS}$ ). None of the children who vomited received analgesics except for one child in the ketamine group who received acetaminophen. One child in the midazolam group experienced nightmares on the first night after surgery. Emergence phenomena were not observed in any of the children during their stay in the recovery room.

The time from the end of surgery until the child was considered fit for discharge home was greater after ketamine premedication than after midazolam premedication $(P<0.05)$ (Table III).

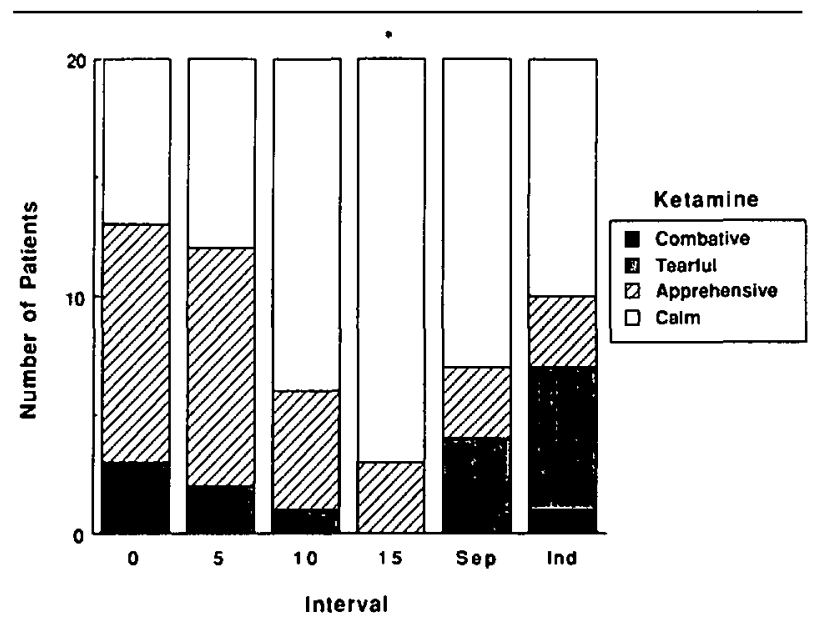

FIGURE 4 The frequency anxiolysis scores after oral ketamine premedication. ${ }^{*} P<0.01$ refers to the number of calm children compared with the baseline frequency.

Thirty-three completed questionnaires $(82.5 \%)$ were returned for analysis. Two questionnaires from children in the midazolam group and five from those in the ketamine group were not returned. Of the 33 questionnaires returned, 31 of the parents responded that their children were "adequately relaxed" at the time of separation, although two parents stated that they would have preferred to wait beyond $20 \mathrm{~min}$ to increase the level of sedation. The parents of ten children who had undergone previous surgery without premedication believed that oral premedication had been of benefit to their children during their surgery. Finally, 29 of the parents suggested that the premedication administered would also benefit their children before subsequent surgery and another two agreed with this notion provided that the flavour of the carrier vehicle could be improved.

\section{Discussion}

We tested the null hypothesis that both oral midazolam and oral ketamine are effective premedications for children one to six years of age scheduled for elective surgery. ${ }^{3,6}$ Our results demonstrate that both premedicants produce sedation and anxiolysis at the time of separation from the parents and application of the face mask. However, post-anaesthetic recovery may be more rapid after midazolam than after ketamine.

We studied a cohort of children who were scheduled for dental surgery for several reasons: (1) these children required general anaesthesia because they were uncooperative in the dental chair or because they had extensive caries; (2) it was possible to use a standardized anaesthetic technique for this type of surgery; (3) a healthy and homogeneous cohort of children could be recruited for inclusion in the study; and (4) intraoperative opioids could 
be avoided by judicious use of local anaesthetic blocks, thereby minimizing the impact of confounding variables during the assessment of recovery. At the conclusion of this study, we were satisfied that this population of children and this type of surgery were appropriate to undertake this comparative trial.

The design of this study may be criticized in that it was not a placebo-controlled trial of two oral premedications. We concede the absence of a placebo treatment group but defend our design: (1) in at least four published studies, the effectiveness of both midazolam and ketamine were compared with placebo and were found to be superior to placebo treatment, ${ }^{1-6}$ (2) we questioned the ethics of including a placebo arm in a study where the superiority of these medications over placebo for preanaesthetic sedation and anxiolysis had been established, and (3) we could not justify on either scientific or ethical grounds, the inclusion of a placebo arm where the null hypothesis was constructed to compare the effectiveness of two premedications.

We were concerned that we may have underestimated our baseline measurements of sedation and anxiolysis in this study. This concern is based on the fact that we measured all baseline values in the ambulatory surgery waiting room after the children had changed their clothing from streetwear to unfamiliar hospital clothing, had been examined by a nurse, had a finger pricked for a preoperative blood test for haemoglobin concentration and had listened to a description of the study given to the parents. Any of these factors alone or in combination may have upset the children who participated in this study and increased their level of agitation and anxiety. Hence, baseline sedation and anxiolysis scores after these interventions may have been smaller (see Table I) than baseline scores before these interventions. As these issues were identified after initiation of the study, their potential contribution to the baseline measurements could not be determined in this study.

The effectiveness of oral midazolam as a sedative and anxiolytic in the young children in this study is consistent with previous reports, ${ }^{14}$ although a recent abstract casted doubts on its superiority over a placebo effect. ${ }^{9}$ Possible explanations for the absence of an effect by midazolam in that abstract include baseline measurements of sedation that were greater than in this study (see above) and that children were separated from their parents at least 20 min after premedication. Absent from the data was the mean time interval between premedication and the time of separation. It is, therefore, difficult to determine whether the effect of midazolam had waned by the time separation occurred. ${ }^{2,7}$ Further insight into the explanation for the lack of effectiveness of midazolam over placebo ${ }^{9}$ will await publication of the manuscript.
Two studies concluded that oral ketamine produces uniform, predictable sedation within 20-25 min of administration, facilitates a calm separation from parents and provides good conditions at induction of anaesthesia. ${ }^{6,10}$ Our results differ in that the proportion of calm children at both separation and induction of anaesthesia after oral ketamine was similar to that at baseline. These differences may be attributed to: (1) a smaller dose of ketamine in this study $\left(5 \mathrm{mg} \cdot \mathrm{kg}^{-1}\right)$ than in other studies $\left(6 \mathrm{mg} \cdot \mathrm{kg}^{-1}\right)^{6,10}$ and (2) our failure to achieve a maximum sedative effect within $20-25 \mathrm{~min}$ of administration. ${ }^{10}$

Post-anaesthetic recovery is difficult to evaluate objectively in pre-school children. In order to quantitate the speed of recovery, we recorded the times from discontinuation of anaesthesia until a specific and objective end-point in recovery was achieved. However, such measurements have their own shortcomings. For example, the interval between discontinuation of anaesthesia and eye opening is influenced by several factors including the severity of pain after dental extractions and by environmental input such as noise and other forms of stimulation in the recovery room. The time to tolerate oral fluids depends, in part, on how frequently the recovery room nurses offer fluids to the children. Despite these shortcomings, we believe that these factors affected both groups similarly and therefore are valid end-points to compare the recovery from premedication and anaesthesia in these two groups of children.

Emergence phenomena have been reported, albeit sporadically, after parenteral ketamine in children. To date, none have been reported after oral administration of ketamine. ${ }^{6,10}$ The absence of emergence phenomena after oral ketamine may be explained by (1) an increased ratio of norketamine to ketamine after oral ketamine, ${ }^{6,11}$ (2) blockade of the side effects of N-methyl-D-aspartate receptor antagonists (such as ketamine) with barbiturates or anticholinergics, ${ }^{12}$ and (3) too limited an experience with oral ketamine to comment on a rare phenomenon. These explanations individually or in combination may explain the absence of emergence phenomena after oral ketamine in this study.

What is the cost/benefit ratio of these oral premedications? The cost of midazolam $\left(0.5 \mathrm{mg} \cdot \mathrm{kg}^{-1}\right)$ premedication based on a $\$ 19.11$ cost for a $10 \mathrm{ml}$ vial (5 $\mathrm{mg} \cdot \mathrm{kg}^{-1}$ ) is $\$ 0.19 \cdot \mathrm{kg}^{-1}$. In comparison, the cost of an equally effective dose of oral ketamine $\left(5 \mathrm{mg} \cdot \mathrm{kg}^{-1}\right)$ based on a $\$ 24.63$ cost for a $10 \mathrm{ml}$ vial $\left(50 \mathrm{mg} \cdot \mathrm{kg}^{-1}\right)$ is $\$ 0.25 \cdot \mathrm{kg}^{-1}$. In conclusion, midazolam and ketamine are equally effective premedicants. However, oral midazolam may be preferable to ketamine because of the shorter recovery and lower cost. 


\section{Acknowledgments}

We thank our dental surgical colleagues, Dr. D. Kenny, Dr. D. Johnston and Dr. P. Judd for their cooperation in conducting this study.

\section{Appendix}

\section{Postoperative parental questionnaire}

1 Did you feel that your child was adequately relaxed at the time he/she was separated from you to enter the operating room?

2 Have you ever accompanied your child to hospital for surgery before?

3 If "yes" to question 2, how do you feel your child's experience was this time compared with the previous one(s)?

4 Would you like your child to have this premedication again prior to surgery?

\section{References}

1 Saarnivaara L, Lindgren L, Klemola U-M. Comparison of chloral hydrate and midazolam by mouth as premedicants in children undergoing otolaryngological surgery. $\mathrm{Br}$ J Anaesth 1988; 61: 390-6.

2 Feld $L H$, Negus $J B$, White $P F$. Oral midazolam in preanesthetic medication in pediatric outpatients. Anesthesiology 1990; 73: 831-4.

3 McMillan CO, Spahr-Schopfer IA, Sikich N, Hartley E, Lerman J. Premedication of children with oral midazolam. Can J Anaesth 1992; 39: 545-50.

4 Parnis SJ, Foate JA, Van der Walt JH, Short T, Crowe $C E$. Oral midazolam is an effective premedication for children having day-stay anaesthesia. Anaesth Intensive Care 1992; 20: 9-14.

5 Rowbottam SJ, Stewart KG, Sudhaman DA, Aitken AW. Oral ketamine (Letter). Anaesthesia 1991; 46: 1084-5.

6 Gutstein $H B$, Johnson $K L$, Heard MB, Gregory GA. Oral ketamine preanesthetic medication in children. Anesthesiology 1992; 76: 28-33.

7 Zar JH. Biostatistical Analysis, 2nd ed. Englewood Cliffs, New Jersey: Prentice-Hall Inc., 1984; 40-52, 126-30, 653-6.

8 Cohen J. Statistical Power Analysis For The Behavioural Sciences, revised ed. Orlando, Florida: Academic Press, Inc., 1977; $19-74$.

9 Vetter TR. A comparison of midazolam and diazepam as oral pediatric anesthetic premedicants. Anesth Analg 1992; 74: $\mathbf{S 3 3 4 .}$

10 Lin YC, Moynihan RJ, Hackel A. A comparison of oral midazolam, oral ketamine, and oral midazolam combined with ketamine as preanesthetic medication for pediatric outpatients. Anesthesiology 1993; 79: A1177.
11 Grant LS, Nimmo WS, Clements JA. Pharmacokinetics and analgesic effects of i.m. and oral ketamine. Br J Anaesth 1981; 53: 805-9.

12 Olney JW, Labruyere J, Wang, G, Wozniak DF, Price MT, Sesma $M A$. NMDA antagonist neurotoxicity: mechanism and prevention. Science 1991; 254: 1515-8. 